\title{
Theta Glutathione S-Transferase Measurement
}

National Cancer Institute

\section{Source}

National Cancer Institute. Theta Glutathione S-Transferase Measurement. NCI

Thesaurus. Code C80207.

The determination of the amount of Theta glutathione-s-transferase present in a sample. 